\title{
Fixed Point Theorems of Quasicontractions on Cone Metric Spaces with Banach Algebras
}

\author{
Hao Liu ${ }^{1}$ and Shaoyuan $X u^{2}$ \\ ${ }^{1}$ School of Mathematics and Statistics, Hubei Normal University, Huangshi 435002, China \\ ${ }^{2}$ Department of Mathematics and Statistics, Hanshan Normal University, Chaozhou 521041, China
}

Correspondence should be addressed to Shaoyuan Xu; xushaoyuan@126.com

Received 5 August 2013; Accepted 23 October 2013

Academic Editor: Simeon Reich

Copyright (c) $2013 \mathrm{H}$. Liu and S. Xu. This is an open access article distributed under the Creative Commons Attribution License, which permits unrestricted use, distribution, and reproduction in any medium, provided the original work is properly cited.

We introduce the concept of quasicontractions on cone metric spaces with Banach algebras, and by a new method of proof, we will prove the existence and uniqueness of fixed points of such mappings. The main result generalizes the well-known theorem of Ćirić (Ćirić 1974).

\section{Introduction}

Let $(X, d)$ be a complete metric space. Recall that a mapping $T: X \rightarrow X$ is called a quasicontraction if, for some $k \epsilon$ $(0,1)$ and for all $x, y \in X$, one has

$$
\begin{gathered}
d(T x, T y) \\
\leqslant k \max \{d(x, y), d(x, T x), d(y, T y), \\
d(x, T y), d(y, T x)\} .
\end{gathered}
$$

Ćirić [1] introduced and studied quasicontractions as one of the most general classes of contractive-type mappings. He proved the well-known theorem that any quasicontraction $T$ has a unique fixed point. Recently, scholars obtained various similar results on cone metric spaces. See, for instance, [2-5].

In this paper, we study the quasicontractions on metric spaces with Banach algebras, which are introduced in [6] and turn out to be an interesting generalization of classic metric spaces. By a new method of proof, we generalize Ćirić theorem.

Let $A$ always be a real Banach algebra with a multiplication unit $e$; that is, $e x=x e=x$ for all $x \in A$. An element $x \in A$ is said to be invertible if there is an inverse element $y \in A$ such that $x y=y x=e$. The inverse of $x$ is denoted by $x^{-1}$. For more details, we refer to [7].

The following proposition is well known (see [7]).

Proposition 1 (see [7]). Let $A$ be a Banach algebra with a unit $e$, and let $x \in A$. If the spectral radius $\rho(x)$ of $x$ is less than 1 , that is,

$$
\rho(x)=\lim _{n \rightarrow \infty}\left\|x^{n}\right\|^{1 / n}=\inf _{n \geqslant 1}\left\|x^{n}\right\|^{1 / n}<1,
$$

then $e-x$ is invertible. Actually,

$$
(e-x)^{-1}=\sum_{i=0}^{\infty} x^{i} .
$$

A subset $P$ of $A$ is called a cone if

(1) $P$ is nonempty closed and $\{0, e\} \subset P$;

(2) $\alpha P+\beta P \subset P$ for all nonnegative real numbers $\alpha, \beta$;

(3) $P^{2}=P P \subset P$;

(4) $P \cap(-P)=\{0\}$.

For a given cone $P \subset A$, we can define a partial ordering $\leqslant$ with respect to $P$ by $x \leqslant y$ if and only if $y-x \in P$. And $x \lessgtr y$ will stand for $x \leqslant y$ and $x \neq y$, while $x<y$ will stand for $y-x \in \operatorname{int} P$, where int $P$ denotes the interior of $P$. 
Remark 2. In the literature on cone metric spaces, authors use $x<y$ to mean $x \leqslant y$ and $x \neq y$ and $x \ll y$ to mean $y-$ $x \in$ int $P$. To our knowledge, and from a topological point of view, the order relation $y-x \in$ int $P$ plays a very similar role in cone metric spaces as $x<y$ does in $\mathbb{R}$.

The cone $P$ is called normal if there is a number $M>$ 0 such that for all $x, y \in A$,

$$
0 \leqslant x \leqslant y \Longrightarrow\|x\| \leqslant M\|y\| .
$$

The least positive number satisfying above is called the normal constant of $P$ (see [8]).

In the following, we always assume that $P$ is a cone in $A$ with int $P \neq \emptyset$ and $\leqslant$ is partial ordering with respect to $P$.

Definition 3 (see [8]). Let $X$ be a nonempty set. Suppose the mapping $d: X \times X \rightarrow A$ satisfies

(1) $0 \leqslant d(x, y)$ for all $x, y \in X$ and $d(x, y)=0$ if and only if $x=y$;

(2) $d(x, y)=d(y, x)$ for all $x, y \in X$;

(3) $d(x, y) \leqslant d(x, z)+d(z, x)$ for all $x, y, z \in X$.

Then, $d$ is called a cone metric on $X$, and $(X, d)$ is called a cone metric space (with Banach algebra $A$ ).

For more details about cone metric spaces with Banach algebras, we refer the readers to [6].

Definition 4 (see [8]). Let $(X, d)$ be a cone metric space, and let $x \in X$ and $\left\{x_{n}\right\}$ be a sequence in $X$. Then,

(1) $\left\{x_{n}\right\}$ converges to $x$ whenever for each $c \in A$ with $0<c$ there is a natural number $N$ such that $d\left(x_{n}, x\right)<c$ for all $n \geqslant N$. We denote this by $\lim _{n \rightarrow \infty} x_{n}=x$ or $x_{n} \rightarrow x$

(2) $\left\{x_{n}\right\}$ is a Cauchy sequence whenever for each $c \in A$ with $0<c$ there is a natural number $N$ such that $d\left(x_{n}, x_{m}\right)<c$ for all $n, m \geqslant N$;

(3) $(X, d)$ is a complete cone metric space if every Cauchy sequence is convergent.

The following facts are often used.

Proposition 5 (see $[8])$. Let $(X, d)$ be a cone metric space, let $P$ be a normal cone with normal constant $M$, and let $\left\{x_{n}\right\}$ be a sequence in $X$. Then, $\left\{x_{n}\right\}$ converges to $x$ if and only if $d\left(x_{n}, x\right) \rightarrow 0(n \rightarrow \infty)$.

Proposition 6 (see [8]). Let $(X, d)$ be a cone metric space, let $P$ be a normal cone with normal constant $M$, and let $\left\{x_{n}\right\}$ be a sequence in $X$. Then, $\left\{x_{n}\right\}$ is a Cauchy sequence if and only if $d\left(x_{n}, x_{m}\right) \rightarrow 0(n, m \rightarrow \infty)$.

\section{Main Results}

In this section we will define quasicontractions in the setting of cone metric spaces with Banach algebras and prove the fixed point theorem of such mappings.
Definition 7. Let $(X, d)$ be a cone metric space with Banach algebra $A$. A mapping $T: X \rightarrow X$ is called a quasicontraction if for some $k \in P$ with $\rho(k)<1$ and for all $x, y \in X$, one has

$$
d(T x, T y) \leqslant k u
$$

where

$$
u \in\{d(x, y), d(x, T x), d(y, T y), d(x, T y), d(y, T x)\} .
$$

Remark 8. In Definition 7, we only suppose the spectral radius of $k$ is less than 1 , while neither $k<e$ nor $\|k\|<1$ is assumed. In fact, the condition $\rho(k)<1$ is weaker than that $\|k\|<1$. See the example in [6].

Theorem 9. Let $(X, d)$ be a complete cone metric space with a Banach algebra $A$, and let $P$ be a normal cone with normal constant $M$. If the mapping $T: X \rightarrow X$ is a quasicontraction, then $T$ has a unique fixed point in $X$. And for any $x \in X$, iterative sequence $\left\{T^{n} x\right\}$ converges to the fixed point.

In the rest of the paper, we choose $x_{0} \in X$ and denote $x_{n}=T^{n} x_{0}$. For the sake of clarity, we divide the proof into several steps.

Lemma 10. Assume that the hypotheses in Theorem 9 are satisfied. Then, for each $n \geqslant 1$, and for all $i, j$ such that $1 \leqslant$ $i, j \leqslant n$, one has

$$
d\left(x_{i}, x_{j}\right) \leqslant k(e-k)^{-1} d\left(x_{0}, x_{1}\right) .
$$

Proof. We present the proof by induction.

When $n=1$, which implies $i=j=1$, the conclusion is trivial.

Assume that the statement is true for $n=m$; that is,

$$
d\left(x_{i}, x_{j}\right) \leqslant k(e-k)^{-1} d\left(x_{0}, x_{1}\right), \quad \text { for } 1 \leqslant i, j \leqslant m \text {. }
$$

Now, we will prove that the statement is true for $n=m+1$. Note that in this case, if $1 \leqslant i, j \leqslant m$, then the statement is just (8). Thus, without loss of generality, we suppose that $j=$ $m+1$ and $1 \leqslant i \leqslant m$ and denote $i=i_{0}$.

By the definition of quasicontraction, we have

$$
d\left(x_{i_{0}}, x_{m+1}\right) \leqslant k u
$$

where

$$
\begin{gathered}
u \in\left\{d\left(x_{i_{0}-1}, x_{m}\right), d\left(x_{i_{0}-1}, x_{i_{0}}\right), d\left(x_{m}, x_{m+1}\right),\right. \\
\left.d\left(x_{i_{0}-1}, x_{m+1}\right), d\left(x_{i_{0}}, x_{m}\right)\right\} .
\end{gathered}
$$

Firstly, we consider the case that $i_{0}=1$; that is,

$$
\begin{gathered}
u \in\left\{d\left(x_{0}, x_{\mathrm{m}}\right), d\left(x_{0}, x_{1}\right), d\left(x_{m}, x_{m+1}\right),\right. \\
\left.d\left(x_{0}, x_{m+1}\right), d\left(x_{1}, x_{m}\right)\right\} .
\end{gathered}
$$




$$
\begin{aligned}
& \text { If } u=d\left(x_{0}, x_{m}\right) \text {, then } \\
& \begin{aligned}
d\left(x_{i_{0}}, x_{m+1}\right) & \leqslant k d\left(x_{0}, x_{m}\right) \\
& \leqslant k\left(d\left(x_{0}, x_{1}\right)+d\left(x_{1}, x_{m}\right)\right) \\
& \leqslant k\left(d\left(x_{0}, x_{1}\right)+k(e-k)^{-1} d\left(x_{0}, x_{1}\right)\right) \\
& =k\left(e+k(e-k)^{-1}\right) d\left(x_{0}, x_{1}\right) \\
& =k\left(e+\sum_{t=1}^{\infty} k^{t}\right) d\left(x_{0}, x_{1}\right) \\
& =k(e-k)^{-1} d\left(x_{0}, x_{1}\right),
\end{aligned}
\end{aligned}
$$

and the statement follows.

If $u=d\left(x_{0}, x_{1}\right)$, then

$$
\begin{aligned}
d\left(x_{i_{0}}, x_{m+1}\right) & \leqslant k d\left(x_{0}, x_{1}\right) \\
& \leqslant\left(\sum_{t=1}^{\infty} k^{t}\right) d\left(x_{0}, x_{1}\right) \\
& =k(e-k)^{-1} d\left(x_{0}, x_{1}\right),
\end{aligned}
$$

and the statement also follows.

If $u=d\left(x_{m}, x_{m+1}\right)$, then we set $i_{1}=m$ and we have

$$
d\left(x_{i_{0}}, x_{m+1}\right) \leqslant k d\left(x_{i_{1}}, x_{m+1}\right) .
$$

If $u=d\left(x_{0}, x_{m+1}\right)$, then

$$
\begin{aligned}
d\left(x_{i_{0}}, x_{m+1}\right) & \leqslant k d\left(x_{0}, x_{m+1}\right) \\
& \leqslant k\left(d\left(x_{0}, x_{1}\right)+d\left(x_{1}, x_{m+1}\right)\right) \\
& =k\left(d\left(x_{0}, x_{1}\right)+d\left(x_{i_{0}}, x_{m+1}\right)\right),
\end{aligned}
$$

which implies

$$
(e-k) d\left(x_{i_{0}}, x_{m+1}\right) \leqslant k d\left(x_{0}, x_{1}\right) .
$$

Note that $(e-k)^{-1}=\sum_{t=0}^{\infty} k^{t} \geqslant 0$ and that $k$ and $(e-$ $k)^{-1}$ commute. Multiplying both sides by $(e-k)^{-1}$, we have

$$
d\left(x_{i_{0}}, x_{m+1}\right) \leqslant k(e-k)^{-1} d\left(x_{0}, x_{1}\right),
$$

and the statement also follows.

If $u=d\left(x_{i_{0}}, x_{m}\right)$, then

$$
\begin{aligned}
d\left(x_{i_{0}}, x_{m+1}\right) & \leqslant k d\left(x_{i_{0}}, x_{m}\right) \\
& \leqslant k^{2}(e-k)^{-1} d\left(x_{0}, x_{1}\right) \\
& =\left(\sum_{t=2}^{\infty} k^{t}\right) d\left(x_{0}, x_{1}\right) \\
& \leqslant\left(\sum_{t=1}^{\infty} k^{t}\right) d\left(x_{0}, x_{1}\right) \\
& =k(e-k)^{-1} d\left(x_{0}, x_{1}\right),
\end{aligned}
$$

and the statement also follows.
Secondly, we consider the case that $2 \leqslant i_{0} \leqslant m$.

If $u=d\left(x_{i_{0}-1}, x_{m}\right)$ or $u=d\left(x_{i_{0}-1}, x_{i_{0}}\right)$ or $u=d\left(x_{i_{0}}, x_{m}\right)$, then, by (8), we have

$$
\begin{aligned}
d\left(x_{i_{0}}, x_{m+1}\right) & \leqslant k u \\
& \leqslant k^{2}(e-k)^{-1} d\left(x_{0}, x_{1}\right) \\
& =\left(\sum_{t=2}^{\infty} k^{t}\right) d\left(x_{0}, x_{1}\right) \\
& \leqslant k(e-k)^{-1} d\left(x_{0}, x_{1}\right),
\end{aligned}
$$

and the statement follows.

If $u=d\left(x_{m}, x_{m+1}\right)$ or $u=d\left(x_{i_{0}-1}, x_{m+1}\right)$, then we set $i_{1}=$ $m$ or $i_{1}=i_{0}-1 \geqslant 1$, respectively. And we have

$$
\begin{aligned}
d\left(x_{i_{0}}, x_{m+1}\right) & \leqslant k u \\
& =k d\left(x_{i_{1}}, x_{m+1}\right) .
\end{aligned}
$$

In conclusion from discussions of both cases, it results that either the proof is complete, that is,

$$
d\left(x_{i_{0}}, x_{m+1}\right) \leqslant k(e-k)^{-1} d\left(x_{0}, x_{1}\right),
$$

or there exists an integer $i_{1}$ such that

$$
d\left(x_{i_{0}}, x_{m+1}\right) \leqslant k d\left(x_{i_{1}}, x_{m+1}\right), \quad 1 \leqslant i_{1} \leqslant m .
$$

As for the latter situation, we continue in a similar way, and come to the result that either

$$
d\left(x_{i_{i}}, x_{m+1}\right) \leqslant k(e-k)^{-1} d\left(x_{0}, x_{1}\right),
$$

which implies that

$$
\begin{aligned}
d\left(x_{i_{0}}, x_{m+1}\right) & \leqslant k d\left(x_{i_{1}}, x_{m+1}\right) \\
& \leqslant k^{2}(e-k)^{-1} d\left(x_{0}, x_{1}\right) \\
& \leqslant k(e-k)^{-1} d\left(x_{0}, x_{1}\right),
\end{aligned}
$$

and the proof is complete, or there exists an integer $i_{2}$ such that

$$
d\left(x_{i_{1}}, x_{m+1}\right) \leqslant k d\left(x_{i_{2}}, x_{m+1}\right), \quad 1 \leqslant i_{2} \leqslant m,
$$

which implies that

$$
d\left(x_{i_{0}}, x_{m+1}\right) \leqslant k^{2} d\left(x_{i_{2}}, x_{m+1}\right), \quad 1 \leqslant i_{2} \leqslant m .
$$

Generally, if the procedure ends by the $\ell$-th step with $\ell \leqslant$ $m-1$, that is, there exist $\ell+1$ integers

$$
i_{0}, i_{1}, \ldots, i_{\ell} \in\{1, \ldots, m\}
$$

such that

$$
\begin{aligned}
d\left(x_{i_{0}}, x_{m+1}\right) & \leqslant k d\left(x_{i_{1}}, x_{m+1}\right) \\
& \leqslant \cdots \leqslant k^{\ell} d\left(x_{i_{l}}, x_{m+1}\right),
\end{aligned}
$$


and such that

$$
d\left(x_{i_{l}}, x_{m+1}\right) \leqslant k(e-k)^{-1} d\left(x_{0}, x_{1}\right),
$$

then

$$
\begin{aligned}
d\left(x_{i_{0}}, x_{m+1}\right) & \leqslant k^{\ell+1}(e-k)^{-1} d\left(x_{0}, x_{1}\right) \\
& =\left(\sum_{t=\ell+1}^{\infty} k^{t}\right) d\left(x_{0}, x_{1}\right) \\
& \leqslant k(e-k)^{-1} d\left(x_{0}, x_{1}\right) .
\end{aligned}
$$

Hence, the proof is complete.

Finally, if the procedure continues more than $m$ steps, then there exist $m+1$ integers

$$
i_{0}, i_{1}, \ldots, i_{m} \in\{1, \ldots, m\}
$$

such that

$$
\begin{aligned}
d\left(x_{i_{0}}, x_{m+1}\right) & \leqslant k d\left(x_{i_{1}}, x_{m+1}\right) \\
& \leqslant \cdots \leqslant k^{m} d\left(x_{i_{m}}, x_{m+1}\right) .
\end{aligned}
$$

Thus, there must exist two integers, $p$ and $q$, say, such that

$$
0 \leqslant p<q \leqslant m, \quad i_{p}=i_{q} .
$$

From (32), one sees that

$$
\begin{aligned}
d\left(x_{i_{p}}, x_{i_{m+1}}\right) & \leqslant k^{q-p} d\left(x_{i_{q}}, x_{m+1}\right) \\
& =k^{q-p} d\left(x_{i_{p}}, x_{m+1}\right),
\end{aligned}
$$

and therefore

$$
\left(e-k^{q-p}\right) d\left(x_{i_{p}}, x_{m+1}\right) \leqslant 0 .
$$

Note that

$$
\rho\left(k^{q-p}\right) \leqslant \rho(k)^{q-p}<1,
$$

which implies $e-k^{q-p}$ is invertible. And since that

$$
\left(e-k^{q-p}\right)^{-1}=\sum_{t=0}^{\infty} k^{(q-p) t} \geqslant 0
$$

we have

$$
d\left(x_{i_{p}}, x_{m+1}\right) \leqslant 0
$$

So,

$$
\begin{gathered}
d\left(x_{i_{p}}, x_{m+1}\right)=0 \\
d\left(x_{i_{0}}, x_{m+1}\right) \leqslant k^{p} d\left(x_{i_{p}}, x_{m+1}\right) \\
=0 \\
\leqslant k(e-k)^{-1} d\left(x_{0}, x_{1}\right)
\end{gathered}
$$

Therefore, by induction, the statement is proved.
Remark 11. Lemma 10 simply says that

$$
d\left(x_{i}, x_{j}\right) \leqslant k(e-k)^{-1} d\left(x_{0}, x_{1}\right), \quad \forall i, j \geqslant 1 .
$$

Lemma 12. Assume that the hypotheses in Theorem 9 are satisfied. Then, $\left\{x_{n}\right\}$ is a Cauchy sequence.

Proof. For $1<m<n$, denote that

$$
C(m, n)=\left\{d\left(x_{i}, x_{j}\right) \mid m \leqslant i, j \leqslant n\right\} .
$$

By the definition of quasicontraction, it follows that, for each $u \in C(m, n)$, there exists $v \in C(m-1, n)$, such that

$$
u \leqslant k v \text {. }
$$

Consequently,

$$
\begin{aligned}
d\left(x_{m}, x_{n}\right) & \leqslant k u_{1} \\
& \leqslant k^{2} u_{2} \\
& \leqslant \cdots \leqslant k^{m-1} u_{m-1} \\
& \leqslant k^{m}(e-k)^{-1} d\left(x_{0}, x_{1}\right),
\end{aligned}
$$

where

$$
u_{1} \in C(m-1, n),
$$

$$
u_{2} \in C(m-2, n), \ldots, u_{m-1} \in C(1, n) \text {, }
$$

and the last inequality comes from Lemma 10 .

By the normality of $P$, and noting that $\left\|k^{m}\right\| \rightarrow 0(m \rightarrow$ $\infty)$, we have

$$
\begin{aligned}
\left\|d\left(x_{m}, x_{n}\right)\right\| \leqslant & M\left\|k^{m}\right\|\left\|(e-k)^{-1}\right\| \\
& \times\left\|d\left(x_{0}, x_{1}\right)\right\| \longrightarrow 0 \quad(n>m \longrightarrow \infty) .
\end{aligned}
$$

The proof is complete.

Now, we finish the remaining part of the proof of Theorem 9.

Proof. By Lemma 12 and the completeness of $(X, d)$, there is $x^{*} \in X$ such that $x_{n} \rightarrow x^{*}(n \rightarrow \infty)$. Then,

$$
\begin{aligned}
d\left(x^{*}, T x^{*}\right) & \leqslant d\left(x^{*}, x_{n}\right)+d\left(x_{n}, T x^{*}\right) \\
& \leqslant d\left(x^{*}, x_{n}\right)+k u,
\end{aligned}
$$

where

$$
\begin{gathered}
u \in\left\{d\left(x_{n-1}, x^{*}\right), d\left(x_{n-1}, x_{n}\right), d\left(x^{*}, T x^{*}\right),\right. \\
\left.d\left(x_{n-1}, T x^{*}\right), d\left(x^{*}, x_{n}\right)\right\} .
\end{gathered}
$$

If $u=d\left(x_{n-1}, x^{*}\right)$ or $u=d\left(x_{n-1}, x_{n}\right)$ or $u=d\left(x^{*}, x_{n}\right)$, then $\|u\| \rightarrow 0(n \rightarrow \infty)$. Hence,

$$
\left\|d\left(x^{*}, T x^{*}\right)\right\| \leqslant M\left\|d\left(x^{*}, x_{n}\right)\right\|+\|k\|\|u\| \longrightarrow 0
$$$$
(n \longrightarrow \infty) \text {. }
$$ 
If $u=d\left(x^{*}, T x^{*}\right)$, then

$$
(e-k) d\left(x^{*}, T x^{*}\right) \leqslant d\left(x^{*}, x_{n}\right) .
$$

Hence,

$$
\begin{array}{r}
\left\|d\left(x^{*}, T x^{*}\right)\right\| \leqslant M\left\|(e-k)^{-1}\right\|\left\|d\left(x^{*}, x_{n}\right)\right\| \longrightarrow 0 \\
(n \longrightarrow \infty) .
\end{array}
$$

If $u=d\left(x_{n-1}, T x^{*}\right)$, then

$$
\begin{aligned}
d\left(x^{*}, T x^{*}\right) & \leqslant d\left(x^{*}, x_{n}\right)+k d\left(x_{n-1}, T x^{*}\right) \\
& \leqslant d\left(x^{*}, x_{n}\right)+k d\left(x_{n-1}, x^{*}\right)+k d\left(x^{*}, T x^{*}\right) .
\end{aligned}
$$

Hence,

$$
\begin{aligned}
\left\|d\left(x^{*}, T x^{*}\right)\right\| & \leqslant M\left\|(e-k)^{-1}\right\| \\
& \times\left(\left\|d\left(x^{*}, x_{n}\right)\right\|+\|k\|\left\|d\left(x_{n-1}, x^{*}\right)\right\|\right) \longrightarrow 0,
\end{aligned}
$$

as $n \rightarrow \infty$.

In each case, we have $\left\|d\left(x^{*}, T x^{*}\right)\right\|=0$. Thus, $T x^{*}=x^{*}$.

Now, if $y^{*}$ is another fixed point, then

$$
d\left(x^{*}, y^{*}\right)=d\left(T x^{*}, T y^{*}\right) \leqslant k u,
$$

where

$$
\begin{gathered}
u \in\left\{d\left(x^{*}, y^{*}\right), d\left(x^{*}, T x^{*}\right), d\left(y^{*}, T y^{*}\right),\right. \\
\left.d\left(x^{*}, T y^{*}\right), d\left(y^{*}, T x^{*}\right)\right\} .
\end{gathered}
$$

If $u=d\left(x^{*}, T x^{*}\right)=d\left(y^{*}, T y^{*}\right)=0$, then $d\left(x^{*}, y^{*}\right)=0$.

If $u=d\left(x^{*}, y^{*}\right)=d\left(x^{*}, T y^{*}\right)=d\left(y^{*}, T x^{*}\right)$, then

$$
(e-k) d\left(x^{*}, y^{*}\right) \leqslant 0,
$$

which implies

$$
d\left(x^{*}, y^{*}\right)=0 .
$$

Thus, the fixed point is unique. And we obtain Theorem 9.

\section{Acknowledgments}

The authors are extremely grateful to the referees for their useful comments and suggestions. The research is partially supported by Doctoral Initial Foundation of Hanshan Normal University, China (no. QD20110920).

\section{References}

[1] L. B. Ćirić, "A generalization of Banach's contraction priciple," Proceedings of the American Mathematical Society, vol. 45, pp. 267-273, 1974.

[2] M. Al-Khaleel, S. Al-Sharifa, and M. Khandaqji, "Fixed points for contraction mappings in generalized cone metric spaces," Jordan Journal of Mathematics and Statistics, vol. 5, no. 4, pp. 291-307, 2012.
[3] L. B. Gajić and V. V. Rakočević, "Quasi-contractions on a nonnormal cone metric space," Functional Analysis and Its Applications, vol. 46, no. 1, pp. 62-65, 2012.

[4] D. Ilić and V. Rakočević, "Quasi-contraction on a cone metric space," Applied Mathematics Letters, vol. 22, no. 5, pp. 728-731, 2009.

[5] Z. Kadelburg, S. Radenović, and V. Rakočević, "Remarks on 'Quasi-contraction on a cone metric space,' Applied Mathematics Letters, vol. 22, no. 11, pp. 1674-1679, 2009.

[6] H. Liu and $\mathrm{S}$. $\mathrm{Xu}$, "Cone metric spaces with Banach algebras and fixed point theorems of generalized Lipschitz mappings," Fixed Point Theory and Applications. In press.

[7] W. Rudin, Functional Analysis, McGraw-Hill, New York, NY, USA, 2nd edition, 1991.

[8] L.-G. Huang and X. Zhang, "Cone metric spaces and fixed point theorems of contractive mappings," Journal of Mathematical Analysis and Applications, vol. 332, no. 2, pp. 1468-1476, 2007. 


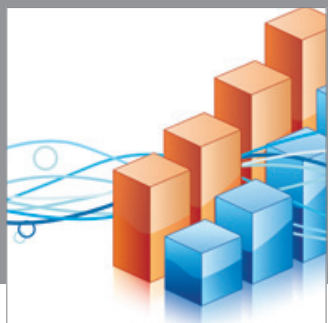

Advances in

Operations Research

mansans

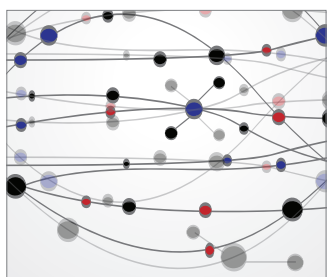

The Scientific World Journal
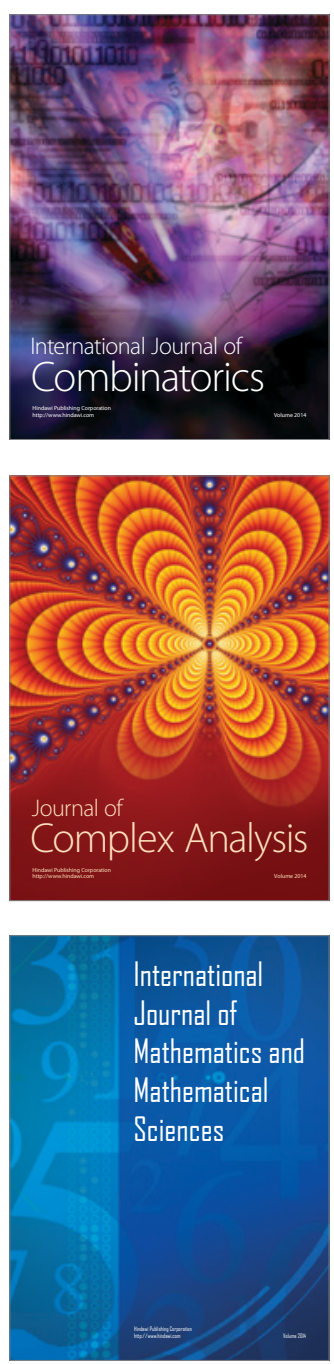
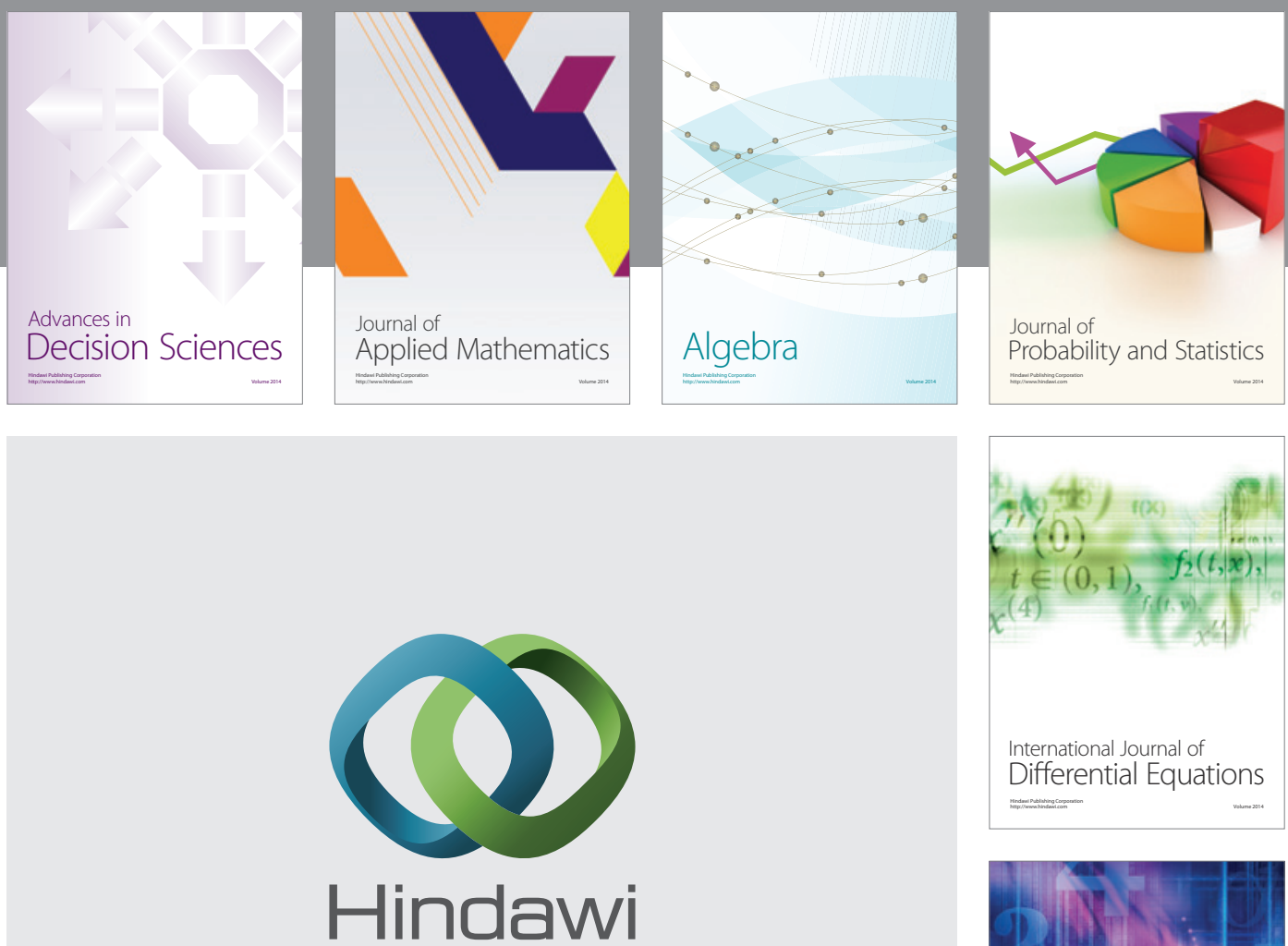

Submit your manuscripts at http://www.hindawi.com
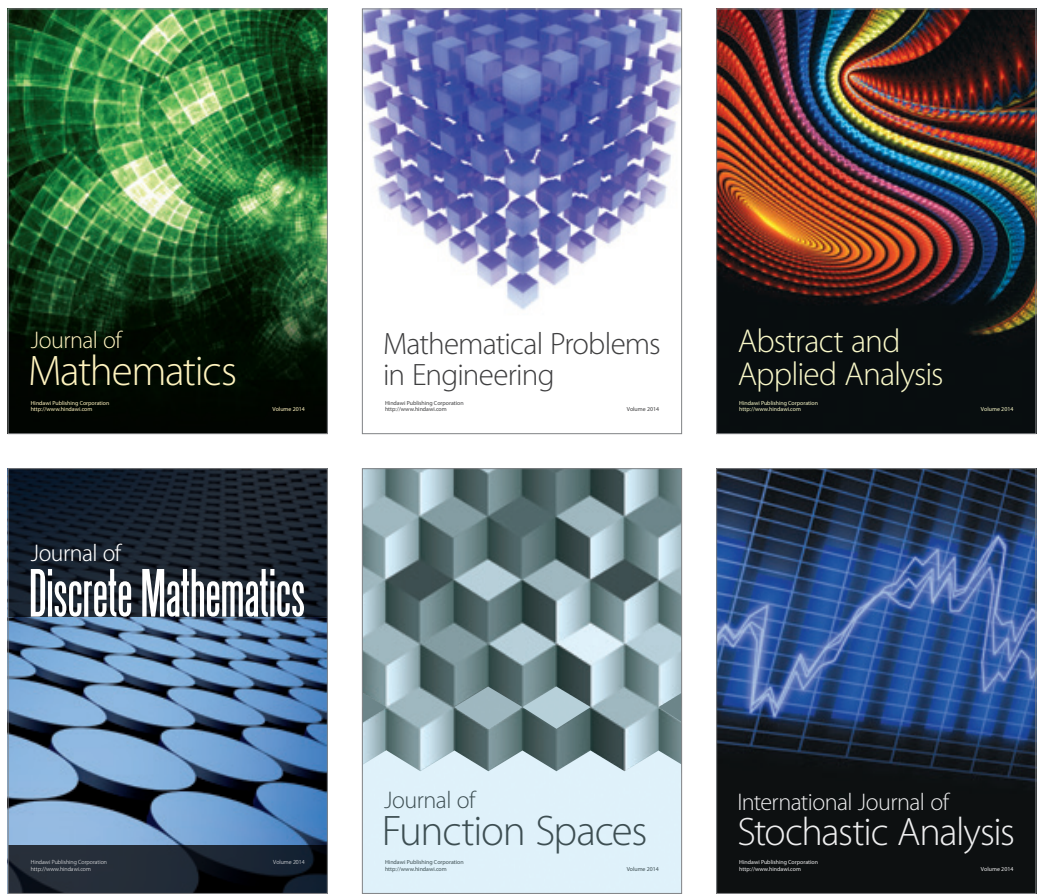

Journal of

Function Spaces

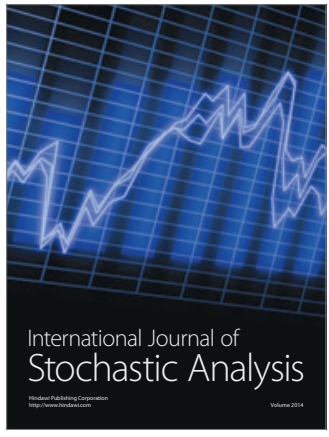

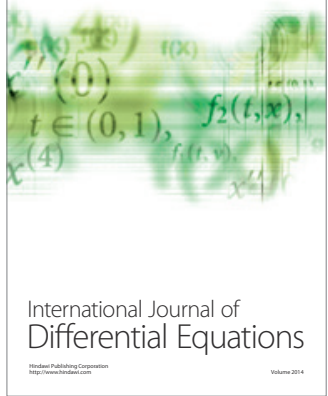
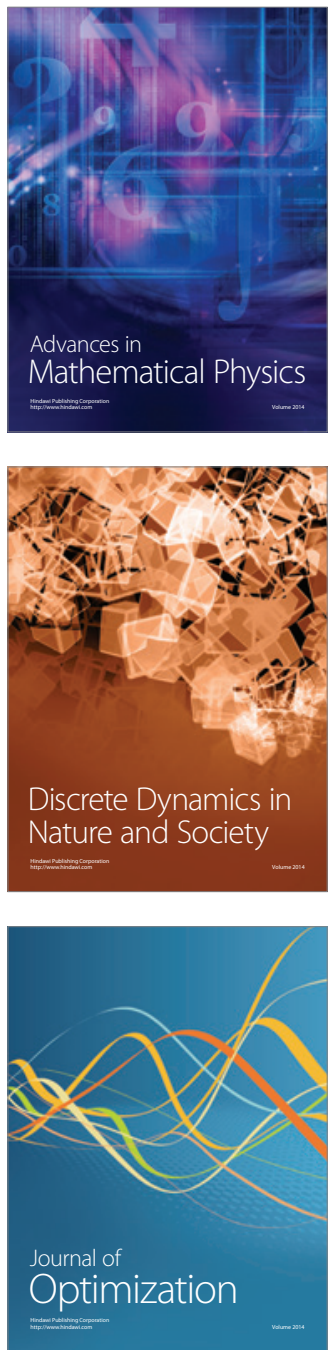